\title{
PENGEMBANGAN MEDIA VIDEO TARI UNTUK MENSTIMULASI PERKEMBANGAN SENI DAN FISIK MOTORIK DI TAMAN KANAK-KANAK
}

\author{
Danang Prastyo ${ }^{\text {a, }}$, Yesi Novitasari ${ }^{\text {b, }}$, \\ ${ }^{a}$ Institut Agama Islam Negeri (IAIN) Madura, Indonesia \\ ${ }^{\mathrm{b}}$ Universitas Lancang Kuning, Indonesia \\ ${ }^{1}$ danang@iainmadura.ac.id; ${ }^{2}$ yesinovitasari@unilak.ac.id;
}

\begin{tabular}{l}
\hline Informasi artikel \\
\hline Received : \\
August 13, 2020 \\
Revised : \\
August 26, 2020. \\
Publish : \\
September 09, 2020. \\
Kata kunci: \\
Perkembangan Seni \\
Fisik Motorik \\
Media Video \\
\end{tabular}

Keywords:

\section{Art Development}

Physical Motor

video media

\begin{abstract}
ABSTRAK
Proses pembelajaran anak usia dini harus mengedepankan perkembangan anak tidak bisa hanya dilihat dari hasil. Oleh karena itu pengalaman nyata dan sarana dalam belajar harus menarik dan dapat dicerna dengan sebaik-baiknya oleh anak agar mendapatkan hasil yang optimal. Kemampuan melakukan gerakan tari penting dilakukan anak karena melalui gerakan tari anak dapat mengekpresikan diri kedalam gerakan-gerakan yang mempunyai makna juga membantu perkembangan seni dan fisik motorik anak. Penelitian ini bertujuan untuk mengetahui kelayakan dan keefektifan media video tari dalam menstimulasi perkembangan seni dan fisik motorik di Taman Kanak-Kanak

Penelitian ini merupakan penelitian pengembangan. Instrumen penelitian yang digunakan adalah observasi, angket dan panduan wawancara. Teknik analisis data yang digunakan dalam penelitian ini adalah uji beda sampel berpasangan ( $t$ - test paired). Dan pengolahan data menggunakan Spss 20. Hasil dalam penelitian ini menunjukkan bahwa: (1) Penggunaan media video tari layak digunakan dalam menstimulasi perkembangan seni dan fisik motorik anak taman-kanak; (2) Penggunaan media video tari efektif dalam menstimulasi perkembangan seni dan fisik motorik di Taman Kanak-kanak
\end{abstract}

ABSTRACT
Early childhood learning process must prioritize children's
development can not only be seen from the results. Therefore real
experiences and facilities in learning must be interesting and can be
digested as well as possible by children in order to get optimal results.
The ability to do dance movements is important for children because
through dance movements children can express themselves into
movements that have meaning that also help the development of children's
art and physical motor skills. This study aims to determine the feasibility
and effectiveness of dance video media in stimulating the development of
motor and physical art in kindergarten children.
This research is a development research. The research instruments
used were observation, questionnaires and interview guides. The data
analysis technique used in this study was paired sample t-test. And
processing data using Spss 20. The results in this study indicate that: (1)
The use of dance video media is appropriate to stimulate the development
of art and physical motor skills of a kindergarten child; (2) The use of
dance video media is effective in stimulating the art and physical
development of kindergarten children




\section{PENDAHULUAN}

Pendidikan Anak Usia Dini khusunya di Taman Kanak-Kanak tidak bisa hanya melihat hasil akan tetapi pengalaman secara nyata dan media yang menarik akan dapat dicerna dengan baik dan akan membantu proses pembelajaran serta perkembangan anak usia Taman Kanak-kanak. Berbagai aspek kemampuan yang harus dikuasai anak disesuaikan dengan Standar tingkat capaian perkembangan anak. Kecerdasan itu sebenarnya bermakna luas, arti kecerdasan sendiri menurut (Mini, 2016:4) adalah keseluruhan kapasitas atau kemampuan untuk belajar memahami lingkungan, dan memecahkan masalah. Kecerdasan yang menyangkut banyak bidang dalam kehidupan kita sehari-hari sering diartikan sebagai kecerdasan majemuk atau Multiple Intellegence.

Anak usia dini bagaikan tunas yang sendang tumbuh, jika kita tidak hati-hati saat menyentuh maka tunas itu akan mati. Dalam perkembangan intelektual anak usia dini banyak bertanya, banyak bergerak. tak jarang pertanyaan anak susah dijawab, gerakan tubuh anak juga sulit dikontrol. Dalam kondisi seperti itu, orang tua atau guru sering memarahi atau melarang bertanya dan melarang kegiatan anak. Hal seperti ini bisa mematikan kreatifitas atau daya kritis anak. jika daya kritis anak sudah mati, maka anak mulai malas bertanya, maka "tunas" yang masih taraf berkembang tersebut akan menjadi layu.

Kemampuan Seni dan Fisik Motorik dapat diperoleh dengan melakukan gerakan tari. Karena melalui gerakan tari anak dapat mengekpresikan gerakan yang bermakna,terarah pada perkembangan anak juga dapat menstimulasi perkembangan seni dan fisik motorik anak. Namun dalam pembelajaran menari di Taman kanakkanak masih banyak kendala. Berdasarkan wawancara dengan beberapa orang guru dan kepala sekolah bahwa pembelajaran menari di Taman Kanak-Kanak masih sangat 
terkendala dengan kemampuan guru dalam mengajarkan tarian, karena guru Taman kanak-kanak bukan dari ahli seni. Sehingga ketika mereka mengajarkan tari anak-anak kurang tertarik untuk melakukan gerakan tari. Kemampuan anak dalam menari menjadi minim sehingga perkembangan seni dan fisik motorik anak kurang dapat berkembang dengan baik.

Dalam kegiatan tari pada usia taman kanak-kanak dapat mengembangkan seni dan fisik motorik anak sesuai dengan tingkat capaian perkembangan anak dalam KI/KD 3.15 mengenal berbagai karya dan aktifitas seni, 4.15 menunjukkan karya dan aktivitas seni. Kemampuan melakukan gerakan tari penting dilakukan anak karena melalui gerakan tari anak dapat mengekpresikan diri kedalam gerakan-gerakan yang mempunyai makna juga membantu perkembangan fisik motorik anak, seperti ditulis dalam buku Orientasi Pendidikan Anak Usia Dini (2013:64) perkembangan fisik : a) kesadaran penuh pada tubuh, b) perkembangan motorik kasar, c) perkembangan motorik halus dengan tujuan utama agar anak mampu menguasai lingkungan melalui peningkatan dari kontrol tubuh dan pengembangan sikap, pengetahuan dan ketrampilan dan perilaku-perilaku yang berhubungan dalam memelihara, menghormati dan melindungi tubuh anak. Melalui gerakan tari pula pikiran anak menjadi terbangun untuk membuat gerakan-gerakan sesuai dengan keinginan dan ekspresi anak.

Gerakan tari yang dilakukan adalah gerakan simbolis, mereka bisa mengungkapkan gagasan, perasaan, atau emosi lewat gerak. Mereka bisa menciptakan sebuah tarian, sandiwara lucu, atau suatu permainan yang mengungkapkan perasaan dan pengalaman mereka. Dengan imajinasi dan pikiran yang terlibat untuk bergerak kreatif, dengan mengontrol ketrampilan motorik, memungkinkan pengungkapan 
simbolis (Seefeldt \& Barbaour ,1998; dan Smith, 2002). Agar pembelajaran tari bisa berhasil secara maksimal maka diperlukan suatu sarana atau media yang dapat membantu dalam pembelajaran. Makna singkat media adalah sarana fisik yang berisi pesan atau sarana untuk menyampaikan pesan (Mustaji 2013:1). Secara umum istilah media berasal dari bahasa latin "Medium" yang berarti perantara atau pengantar yaitu perantara atau pengantar pesan dari pengirim ke penerima (Sadiman, 2002:6) para ahli mencontohkam, media itu sebagai alat atau sarana yang dapat menunjang dalam proses pembelajaran seperti buku, film, kaset, film bingkai (slide film), televise, computer, CD Video, dsb. Briggs (dalam modul gp 2016) mengatakan bahwa media pembelajaran adalah sarana fisik yang dapat menyajikan pesan atau menyampaikan isi/ materi sehingga merangsang siswa untuk belajar. Demikian juga Wilbur Schramm mengemukakan bahwa media pembelajaran adalah tehnologi pembawa pesan yang dapat dimanfaatkan untuk keperluan belajar. Gagne juga mengatakan bahwa media adalah berbagai jenis komponen dalam lingkungan siswa yang dapat merangsangnya untuk belajar. Bila media tidak disediakan komunikasi akan sulit terjadi dan pembelajaran tidak akan berlangsung secara optimal, karena media pembelajaran adalah integral (komponen yang tidak dapat dipisahkan) dari sistem pembelajaran.

Dengan disediakannya media sebagai sarana penunjang dalam proses pembelajaran diharapkan dapat menjadi stimulasi dan intervensi guru sesuai dengan kebutuhan anak. Karena dalam usia prasekolah anak akan lebih tertarik serta lebih cepat dalam mempelajari sesuatu yang dapat diinderanya, baik dengan cara melihat, mendengar, meraba, mencium dan merasakan secara langsung. Dalam pemilihan media pembelajaran seorang guru hendaknya mempertimbang kan berbagai aspek. Pendekatan yang relevan dengan kurikulum yang dipergunakan saat ini merupakan 
pertimbangan utama, dengan kurikulum K13 dengan KTSP nya maka guru diberi otoritas untuk memberikan pengembangan dan penguatan kompetensi-kompetensi tertentu. Artinya, kemampuan seorang guru dalam hal pemilihan dan pemanfaatan media untuk kegiatan pembelajaran tentunya merupakan suatu keharusan. Untuk memudahkan pemilihan media pembelajaran harus terlebih dahulu menyesuaikan dengan tema-tema yang telah dibuat. Berdasarkan dari tema-tema dan tujuan pembelajaran maka kriteria-kriteria pemilihan media dilakukan. Kriteria-kriteria yang telah dibuat antara lain (Munadi, 2013:187) karakteristik siswa, tujuan pembelajaran, bahan ajar, karakteristik medianya itu sendiri, dan sifat pemanfaatan media.

Media tersebut adalah media video. Video yang akan dikembangkan adalah berupa Digital Video Disk. Digital Video Disk adalah sarana menyimpan dan mencari kembali gambar (Munadi,2013). Video Compact Disk, yang kebanyakan orang mengenalnya sebagai VCD. Video digital ini memanfaatkan format medium CD yang sebelumnya sudah dikenal luas dalam format audio CD. Melalui media video CD yang bersifat interaktif tutorial membimbing peserta didik untuk memahami sebuah materi melalui visualisasi. Peserta didik dapat secara interaktif mengikuti kegiatan praktek sesuai yang diajarkan dalam video. Kelebihan dari media video yang lainnya adalah kemampuan video dalam memvisualisasikan materi terutama efektif untuk membantu guru dalam menyampaikan materi yang bersifat dinamis. Materi yang memerlukan visualisasi yang mendemonstrasikan hal-hal seperti gerakan motorik tertentu, ekspresi wajah, atau suasana lingkungan tertentu adalah paling baik disajikan menggunakan video pembelajaran. Media Video tari diperlukan untuk menstimulasi perkembangan seni dan fisik motorik anak. Sesuai dengan penelitian Daryanto (2013:86) bahwa Video merupakan medium yang sangat efektif dalam membantu 
pembelajaran. Media Video yang dikembangkan adalah media yang menyajikan visual gerak, melalui media video ini anak dapat menyaksikan gambar yang bergerak, berwarna dan bersuara. Informasi yang disajikan melalui media video ini berbentuk dokumen yang hidup. Dapat dilihat dilayar monitor dapat didengar suaranya dan gambarnya dapat dilihat dan ditirukan gerakannya (Arsyad 2015:162). Anak memerlukan media video tari, karena dengan menggunakan media video ini anak-anak akan merasa senang bisa melihat gambar yang bergerak dan mendengarkan suaranya serta menirukan gerakannya, guru menjadi terbantu dalam memberikan pembelajaran tarian, pembelajaran menjadi lebih mudah dan menyenangkan.

\section{METODE}

Penelitian ini merupakan penelitian pengembangan (Research and Development) dari model Dick and Carrey yang menggunakan model procedural yang bersifat deskriptif, yakni menggariskan langkah-langkah yang harus dilakukan untuk menghasilkan suatu produk. Pemilihan model pengembangan menggunakan model Dick and Carey (2003). Dalam pengembangan ini menghasilkan produk berupa Video tari dengan melalui 10 tahap yaitu (1) Identity Instructional Goal (s) (2) Conduct Instructional Analysis (3) Analyze Learners and context (4) Write performance objectives (5) Develop Assesment instrumen (6) Develop Instructional Strategi (7) Develop and select Instuctional Material (8) Design and conduct formative Evaluation of instruction (9) Revise Instuction

(10) Desain and Conduct Sumative.

Penelitian ini dilakukan di Taman Kanak-kanak kecamatan Paciran kabupaten Lamongan. Dengan sampel penelitian pada anak Taman kanak-kanak kelompok B. Untuk Pengolahan data diambil dari hasil uji coba perorangan, uji coba kelompok 
kecil, dan uji coba lapangan dan uji ahli digunakan data sebagai berikut : a) validasi ahli yakni analisis data tentang kepatutan, kemenarikan, kwalitas gambar, dan kwalitas suara pada media yang di desain. b) tahap uji coba kelompok kecil untuk melihat kemenarikan media terhadap anak, dan mengetahui respon awal anak. Subyek penelitian ini tiga orang anak. c) tahap uji coba kelopmpok besar tahap ini bertujuan untuk mengidentifikasi masalah yang belumn tertuntaskan setelah melewati kelompok kecil, dengan tujuan menggunakan media video pembelajaran untuk kegiatan menirukan tarian pada konteks yang sebenarnya. Pada validasi ahli ini menggunakan skala Guttman yang kemudian dikembangkan sendiri. Keefektifan media video tari dapat diketahui hasinya dengan membandingkan hasil dari pencapaian sebelum pembelajaran (pretest) dan sesudah pembelajaran (posttest). Dengan mengunakan statistik inferensial. Desain uji coba yang digunakan adalah One Group Pretest- Posttes Design.

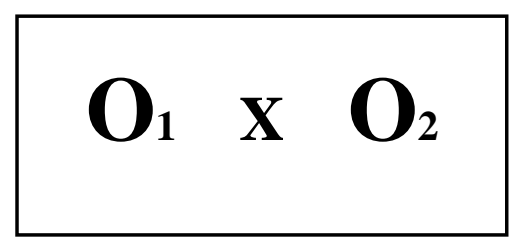

\section{Desain Eksperimen One-Group Pretest-Posttest Design} (Sugiyono, 2015:163)

Uji normalitas diukur dengan Uji beda sampel berpasangan ( $t$-test paired) digunakan untuk membandingkan rata-rata dua variabel dengan satu kelompok. Perbedaan rata-rata harus terdistribusi normal (Sarwono 2009, dalam Candra, 2015:92). Kemudian dari hasil yang telah diperoleh berupa data selanjutnya akan dianalisis menggunakan software SPSS 20. Alasan peneliti menggunakan desain one 
grup pretest posttest untuk memperoleh keefektifan perlakuan terhadap pengukuran awal dan pengukuran akhir. Hal tersebut sesuai dengan pendapat Suryabrata (2014:102) bahwa desain one grup pretest posttest bertujuan untuk memberikan komparasi prestasi subyek yang sama sebelum dan sesudah dikenai X (experimental treatment). Dengan demikian desai tersebut tepat untuk digunakan dalam memperoleh hasil yang efektif dalam pengembangan media video tari untuk menstimulasi perkembangan seni dan fisik motorik anak taman kanak-kanak.

\section{PEMBAHASAN}

Dari hasil analisis data setelah melalui sembilan prosedur dalam Dick and Carrey yang meliputi (1) analisis uji coba perorangan; (2) analisis uji coba kelompok kecil ; (3) analis uji coba kelompok besar, (4) uji validasi ahli; uji normalitas. Pada hasil uji coba kelompo kecil terdapat hasil pretes dengan nilai rata-rata 1,73, nilai tertinggi 1. 80 dan nilai terendah 1.70. pada perkembangan seni dan pada perkembangan fisik motorik terdapat nilai rata-rata 1.61 dengan nilai tertinggi 1.71 dan nilai terendah 1.50 . setelah melalui posttest maka stimulasi perkembangan seni terdapat hasil rata-rata 1.86, nilai tetinggi 1.90 dan nilai terendah 1.80. sedangkan pada stimulasi perkembangan fisik motorik saat pretest nilai rata-rata adalah 1.61 setelah

Pada hasil uji coba kelompok kecil pada stimulasi perkembangan seni pretest data hasil uji coba pretest terdapat nilai rata-rata 1.52 setelah postest 1.63 terjadi peningkatan nilai 0.11 , nilai tertinggi prestest 1.70 dan nilai postes 1.80 terjadi peningkatan 0.10 , nilai terendah pretest 1.30 setelah posttest 1.40 terdapat kenaikan 0.10.Selanjutnya pada data hasil uji coba kelompok kecil pada stimulasi perkembangan fisik motorik pretest nilai rata-rata pretest 1.90 setelah posttest 2.16 
terjadi kenaikan 2.16, nilai tertinggi pretest 2.00 setelah posttest 2.42 terjadi kenaikan 0.42 , nilai terendah pretest 1.57 setelah posttest 2.00 sehingga terjadi kenaikan 0.43 .

Uji validitas media pada kelayakan media video telah dinyatakan layak dan valid untuk digunakan sebagai media pembelajaran tari. Hasil analisis menunjukkan bahwa terdapat perbedaan perkembangan seni dan fisik motorik anak antara sebelum dan sesudah diberi perlakuan media video pembelajaran menari. Hal ini menunjukkan adanya pengaruh perlakuan media video pembelajaran menari terhadap perkembangan seni dan fisik motorik anak. Perkembangan seni anak sesudah diberi perlakuan media video pembelajaran menari lebih besar daripada perkembangan seni anak sebelum diberi perlakuan menggunakan media video pembelajaran menari $(2.3240>1.616)$. Maka dapat disimpulkan bahwa ada beda perkembangan seni anak setelah siswa diberi stimulasi media video pembelajaran menari.

Perkembangan fisik motorik anak sesudah diberi perlakuan media video pembelajaran menari lebih besar daripada perkembangan fisik motorik anak sebelum diberi perlakuan media video pembelajaran menari $(2.1564>1.7372)$. Maka dapat disimpulkan bahwa ada beda perkembangan fisik motorik anak setelah siswa diberi stimulasi menggunakan media video pembelajaran tari.

Penelitian ini membuktikan bahwa penggunaan media pembelajaran melalui video tari mampu menstimulasi perkembangan seni dan fisik motorik anak. Sehingga dapat disimpulkan bahwa penerapan media video tari dalam menstimulasi perkembangan seni dan fisik motorik anak efektif digunakan. Hal ini sependapat dengan penelitian Daryanto (2013:86), dimana video merupakan suatu medium yang efektif untuk membantu proses pembelajaran, baik untuk pembelajaran massal, individual maupun berkelompok. Selain itu kelebihan dari media video yang lainnya 
adalah kemampuan video dalam memvisualisasikan materi terutama efektif untuk membantu guru dalam menyampaikan materi yang bersifat dinamis.

Materi yang memerlukan visualisasi yang mendemonstrasikan hal-hal seperti gerakan motorik tertentu, ekspresi wajah, atau suasana lingkungan tertentu adalah paling baik disajikan menggunakan video pembelajaran. Oleh karena itulah materi yang telah direkam dalam bentuk video dapat digunakan baik untuk proses belajar tatap muka secara langsung maupun jarak jauh tanpa kehadiran guru. Hal itu juga dikuatkan dalam penelitian Singh Shilpa, Mishra Sunita (2013, Vol 2) bahwa media video ini memainkan peran yang sangat penting membantu siswa dalam proses belajar dan berpengaruh positif pada pendidikan anak usia dini (3-6) tahun..

\section{KESIMPULAN}

Berdasarkan hasil penelitian yang telah dilakukan maka dapat disimpulkan bahwa (1) Media video tari layak digunakan dalam menstimulasi perkembangan seni dan fisik motorik anak Taman Kanak-Kanak, (2) Penggunaan media video tari efektif dalam menstimulasi perkembangan seni dan fisik motorik anak Taman Kanak -kanak. 


\section{REFERENSI}

Basuki, Ismet, Hariyanto. (2014). Asesmen Pembelajaran, Bandung : PT Remaja Rosda Karya

Cheppy Riyana. 2007. Pedoman Pengembangan Media Video. Jakarta: P3AI UPI.

Creswell, John W. (2014). Research Design Pendekatan Kualitatif, Kuantititatif, dan Mixed. Yogjakarta : Pustaka Pelajar.

Daryanto. (2013). Media Pembelajaran. Yogjakarta: Gava Media

Dick and Carrey. (2001), Model Pengembangan Sistem Pembelajaran Dick And Carry, New York:Education Publishher

Singh Shilpa, Mishra Sunita. (2013). A Study About Role of Multi Media in Early Chilhood Education, 2319- 7714, abstrak diperoleh dari www.ijhssi.org volume 2,issue 6/juni.2013/PP.80-85 